\title{
Sistemas de abastecimento em comunidades rurais do semiárido: a implantação do SISAR em Cristais, Cascavel, CE
}

\author{
Rural water supply in Semiarid: the implementation of SISAR in \\ Cristais, Cascavel, $C E$
}

\section{Francisco Glauber César \\ Alves \\ gbcesar@uol.com.br \\ Universidade de Fortaleza}

Flávia Telis de Vilela Araújo

flaviatelis@globo.com

Universidade de Fortaleza/

Centro Universitário Estácio

do Ceará

\begin{abstract}
Resumo
Este trabalho tem como objetivo estudar a problemática do acesso e universalização de água para consumo humano nas pequenas comunidades rurais difusas do Semiárido brasileiro, não incluídas nas grandes obras de infraestrutura hídrica, a partir da análise da implantação do Programa de Saneamento Rural Integrado (SISAR), no Distrito rural de Cristais, localizado no município de Cascavel, Ceará. Programas de acesso à água, tais como a construção de cisternas rurais, utilização de carros pipa e o SISAR têm buscado, ao longo dos últimos anos, promover o acesso de água, embora nem sempre em quantidade e qualidade satisfatórias. O SISAR, que tem como um dos princípios a participação comunitária no gerenciamento do sistema de saneamento local, começou a ser implantado no Ceará em 1996, na Bacia do Acaraú e Coreaú. Atualmente, existem oito unidades do Programa no Estado, nas bacias hidrográficas, beneficiando aproximadamente 435 mil pessoas. O impacto da implantação do SISAR em Cristais incluiu uma pesquisa bibliográfica e levantamento de dados existentes sobre o programa e a legislação relacionada, realização de observações de campo, tratamento e análise das informações. O SISAR demonstrou ser uma solução viável, a partir da participação da comunidade local nas etapas de planejamento, implantação e gestão, assim como o aumento da abrangência do sistema de abastecimento e a melhoria dos parâmetros de qualidade da água, relacionada diretamente com a melhoria da qualidade de vida dos habitantes. Entretanto, observou-se que fatores culturais impedem que uma parcela da população, que não se atentam para a importância do sistema, e, portanto, não fazem uso do mesmo, prosseguem utilizando tecnologias obsoletas de acesso à água, continuando em condições de vulnerabilidade hídrica.
\end{abstract}

Palavras-chave: SISAR. Abastecimento Rural. Semiárido.

\begin{abstract}
This report aims to study the problem of access and universal water for human consumption in small diffuse rural communities in the Brazilian semiarid region, not included in the great works of water infrastructure, from the analysis of the implementation of the Integrated Rural Sanitation Program (SISAR) in the rural district of Cristais, located in Cascavel, Ceará. Program access to water, such as the construction of rural cisterns, use of pipa cars and SISAR have sought over the years to promote water access to, although not always satisfactory in quantity and quality. The SISAR, which has as one of the principles of community participation in the management of the local sanitation system began to be implemented in Ceará in 1996 in hydrographic basin Acaraú and Coreaú. Currently, there are eight units of the program in the state, watersheds, benefiting approximately 435,000 people. The impact of SISAR deployment in Cristais included a literature review and survey of existing data, conducting field observations and analysis of information. The SISAR proved to be a viable solution from the local community participation in the stages of planning, implementation and management, as well as increasing the supply system coverage and the improvement of water quality parameters, directly related to the improvement of quality of life of the inhabitants. However, it was noted that cultural factors prevent a portion of the population who does not care for the importance of the system, and therefore do not make use of it, continue using obsolete technologies of access to water, continuing water vulnerable conditions.
\end{abstract}

Keywords: SISAR. Rural Water Supply. Semiarid. 


\section{Introdução}

No Brasil, a Constituição Federal (BRASIL, 1988), e as Políticas Nacionais de Recursos Hídricos (Lei 9.433/97) e de Saneamento Básico (Lei 11.445/2007) asseguram a universalização do acesso aos recursos hídricos e aos serviços de saneamento, incluindo o abastecimento humano, inclusive às populações rurais e de pequenos núcleos urbanos isolados (BRASIL, 1997; 2007). Compete à Fundação Nacional de Saúde (FUNASA), a implantação das ações de saneamento em áreas rurais em todos os municípios brasileiros.

Segundo o Instituto Brasileiro de Geografia e Estatística (IBGE, 2010), no País, cerca de 29,9 milhões de pessoas residem em localidades rurais; aproximadamente $33,2 \%$ dos domicílios rurais estão ligados a redes de abastecimento de água, com ou sem canalização interna. No restante dos domicílios rurais $(66,8 \%)$, a população capta água de chafarizes e poços protegidos ou não, diretamente de cursos de água sem nenhum tratamento, ou de outras fontes alternativas, tais como cisternas, carros pipa, geralmente não atendendo aos padrões de potabilidade (BRASIL, 2011).

No semiárido brasileiro, a escassez de água para o consumo humano é um drama social recorrente, vivenciado principalmente durante as secas, que torna as populações extremamente vulneráveis ao evento climático. Nesses períodos, a necessidade diária de se buscar água para o consumo doméstico obriga, sobretudo as mulheres e crianças, a longas caminhadas. Dos 3,5 milhões de domicílios rurais do Nordeste (IBGE, 2010), é provável que mais de dois terços se encontrem em tal situação.

As secas tendem a aumentar a vulnerabilidade dos ecossistemas naturais da região semiárida à degradação, refletindo diretamente na oferta hídrica. As comunidades rurais, que representam $26,9 \%$ da população (IBGE, 2010), são afetadas pela escassez de água, que comprometem também o desenvolvimento de atividades econômicas, principalmente as agropecuárias, aumentando os níveis de pobreza e desigualdade (ARAÚJO, NUNES, SOUZA FILHO, 2014).

Dentre as questões relacionadas à baixa cobertura de abastecimento em áreas rurais encontram-se a localização das mesmas, que dispersas ao longo do território, tornam a implantação e operação do sistema inviáveis do ponto de vista financeiro, não retornando lucros às companhias de abastecimento, além da água ter funcionado como instrumento de troca de votos.

Em 154 comunidades rurais de três municípios do sertão do Ceará, nas quais se realizou um levantamento de informações referentes à forma de abastecimento, observou-se que $39 \%$ das comunidades situavam-se em criticidade máxima, isto é, não dispunham de uma fonte segura de abastecimento hídrica primária, e eram caracterizadas pela dependência total de cisternas e abastecimento com carro pipa, no segundo semestre do ano. Observou-se ainda que, quanto maior o número de famílias da comunidade melhor seria a situação do abastecimento, e, portanto, quando menor a comunidade, maior sua vulnerabilidade hídrica, pois a magnitude da escala do sistema é definida pelo número de famílias a ser atendida e impacta diretamente nos custos de investimento e no rateio dos custos de operação e manutenção das soluções coletivas (DANTAS NETO, SILVA, SOUZA FILHO, 2013).

Ademais, o que se verifica no Semiárido é que muitos reservatórios de água, os açudes, que foram construídos com recursos públicos e que deveriam servir de uso comum, principalmente para o abastecimento de comunidades rurais, foram revertidos a bens privados pelas elites econômicas e políticas locais impedindo o acesso universal a quem dela precisa (SILVA, 2011).

No Estado do Ceará, que possui $80 \%$ de sua área territorial inserida no Semiárido brasileiro, o índice de cobertura com abastecimento de água potável nas zonas urbanas é de $92,14 \%$, enquanto que na zona rural é de 18,88\%. Em termos quantitativos, enquanto 498.839 habitantes não têm acesso à água potável em zonas urbanas no Ceará, na zona rural, o número é de 1.708.244 pessoas (CAGECE, 2014).

Como ação para melhorar os indicadores negativos de saneamento e saúde humana no meio rural no Ceará, foi criado, em 1996, o Sistema Integrado de Saneamento Rural do Ceará (SISAR/CE), uma associação civil de direito privado, sem fins lucrativos, dotada de personalidade jurídica, regida pelo Código civil brasileiro, e formada pelas associações das comunidades sob sua responsabilidade, estabelecido mediante um acordo de cooperação financeira entre o Governo Alemão, através do Banco Kreditanstalt für Wiederaufbau $(K f W)$, o Banco Mundial e o Governo do Estado do Ceará. A Companhia de Água e Esgoto do Estado do Ceará (CAGECE) é o órgão executor das ações, e o Governo Federal atua como avalista (ALVES, 2015). 
O SISAR surgiu da necessidade de se assegurar que os sistemas de abastecimento de água de comunidades rurais, frequentemente criados graças a programas estaduais, dentre eles o Projeto $K f W$, tivessem sustentabilidade ao longo do tempo, assegurando uma vida útil prevista de vinte anos.

O SISAR constitui-se de um mecanismo institucional para implantar o sistema de saneamento, no que se refere à água e esgoto na comunidade rural, incentivar a autogestão por parte da população local e a sustentabilidade do mesmo. O SISAR é limitado aos núcleos populacionais rurais na faixa de 50 até 250 famílias. Não existe ainda acompanhamento público para a gestão de pequenos sistemas abaixo de 50 famílias (ALVES, 2015; ARAÚJO et al., 2016).

A estrutura administrativa do SISAR é composta por uma assembleia geral (órgão máximo), um conselho administrativo, um conselho fiscal, com participação da comunidade local, uma auditoria técnica (CAGECE) e uma gerência executiva composta pelas equipes de capacitação, da área financeira e de manutenção. Além disso, recebe assessoria técnica de consultores contratados pelo $K f W$.

O SISAR representa uma alternativa à privatização dos serviços de saneamento, proporcionando um modelo de gestão que se enquadra na esfera pública, com os benefícios da parceria governo/comunidade. Tal modelo permite a transferência de responsabilidades aos usuários pela manutenção de seus bens comuns e a redução das despesas públicas.

O modelo é baseado na ideia de criar uma confederação de grupos de usuários locais, que se reúnem numa base regional, e através de uma estrutura institucional adequada, são responsáveis pela gestão SISAR e assegurar o fornecimento adequado de abastecimento de água e em alguns casos, serviços de águas residuais (MELEG, 2011; MELEG, 2012; ROCHA, 2013).

O SISAR visa garantir, no prazo de 20 anos, o desenvolvimento e manutenção dos sistemas implantados pela CAGECE de forma autossustentável. Cada um desses sistemas constitui uma Organização Não Governamental sem fins lucrativos, formada pelas associações comunitárias representando as populações atendidas.

Desde sua criação, o Programa foi retomado várias vezes, a fim de se implantar um total de oito sistemas, beneficiando 1.124 comunidades e um total de 435 mil habitantes (CAGECE, 2014) nas distintas regiões hidrográficas do estado do Ceará.

Albuquerque Neto (2011) ao analisar a sustentabilidade financeira do SISAR verificou que o mesmo, ao prestar um serviço de abastecimento de água de boa qualidade, apresenta viabilidade financeira para suprir seus custos e despesas e promover pequenas ampliações de sistema, se contemplar um maior número de domicílios atendidos que lhe proporcione ganhos de escala.

Este trabalho tem como objetivo estudar o impacto do Sistema de Saneamento Rural (SISAR) como alternativa viável para aumentar o acesso da população e a sustentabilidade do abastecimento hídrico de pequenas comunidades rurais difusas do Semiárido brasileiro, a partir do estudo de caso do Distrito de Cristais, localizado no município de Cascavel, no Estado do Ceará.

\section{Metodologia}

A partir da prévia pesquisa exploratória e do estudo de um caso concreto, tendo sido realizadas algumas observações de campo, foi possível estudar o impacto da implantação do SISAR na busca da melhoria do abastecimento rural em comunidades rurais dispersas no Semiárido brasileiro.

A comunidade rural estudada foi a do Distrito Rural de Cristais, que possui uma área de $5,53 \mathrm{~km}^{2}$, e está localizado no município de Cascavel no Estado do Ceará (FIGURA 1).

O Distrito de Cristais possui 1.578 habitantes (IBGE, 2010); quando dos estudos de projeção para implantação do SISAR, para um horizonte de 20 anos, foi estimado um crescimento de $2 \%$ ao ano, que resultou em uma população, no ano de 2031, de 2.344 residentes. 
Figura 1 - Localização do Distrito de Cristais, Município de Cascavel, Estado do Ceará, Brasil.
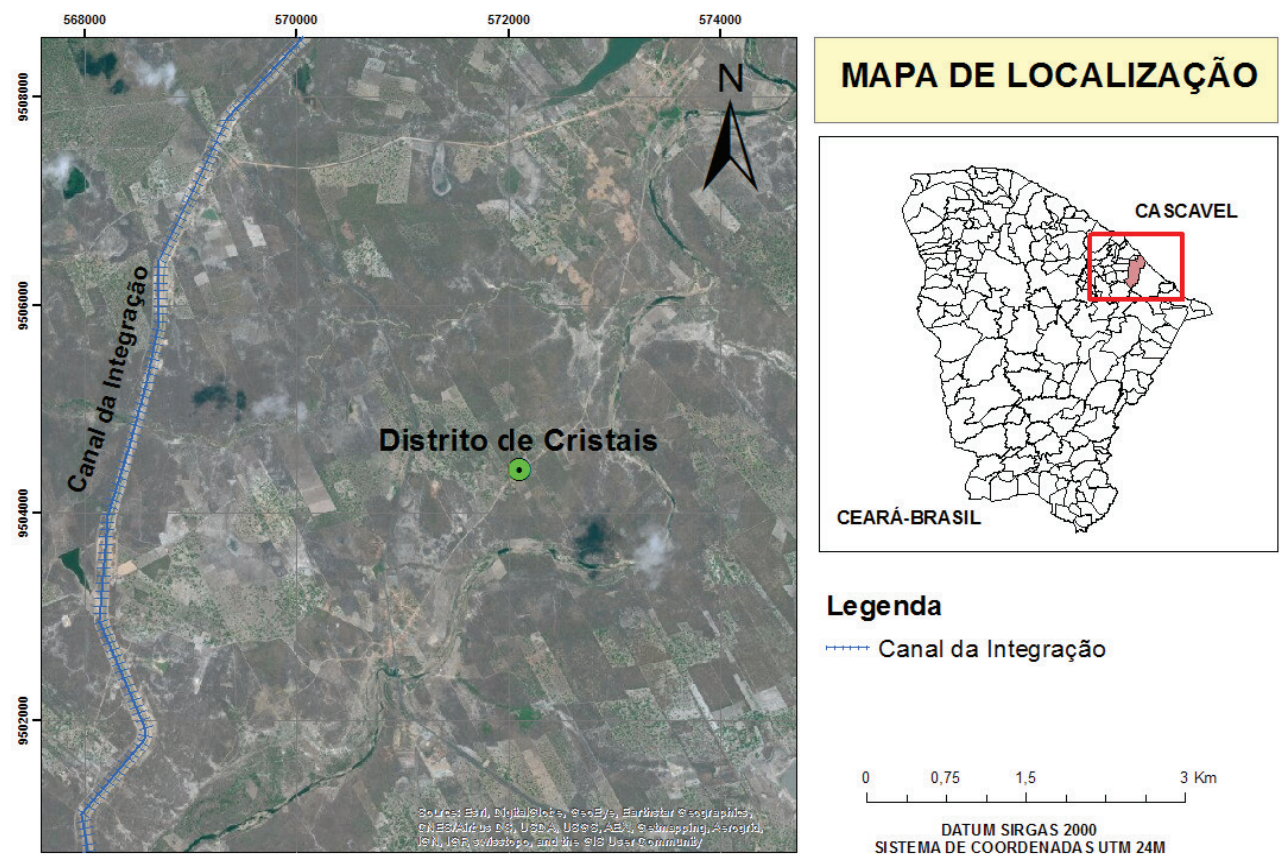

Fonte: elaboração própria (2016).

Além da observação em campo, a pesquisa compreendeu a coleta de dados juntamente ao SISAR ${ }^{1}$, à CAGECE, e dos dados cedidos pelo Programa de Pesquisa e Inovação Tecnológica da União Europeia (DESAFIO)².

Optou-se por analisar o impacto do SISAR na comunidade, a partir de indicadores relacionados à qualidade e acesso à água para abastecimento.

O estudo exploratório e de observação de campo foi o mais adequado para este trabalho, pois ele objetivou aprofundar e ampliar o conhecimento sobre o SISAR, e identificar os benefícios e dificuldades encontradas pela comunidade em questão.

As atividades relacionadas ao desenvolvimento deste trabalho incluíram:

- Levantamento bibliográfico a partir da consulta das informações existentes sobre o programa, assim como da legislação relacionada.

- Levantamento de dados existentes.

- Atividade de campo no Distrito de Cristais.

- Tratamento e análise dos dados.

\section{Resultados e discussão}

No Estado do Ceará, o modelo de acumulação das águas em grandes açudes estratégicos para regularização dos rios e atendimento às grandes demandas concentradas de zonas urbanas - abastecimento humano, industrial e comercial, e perímetros de irrigação tem se mostrado satisfatório, como uma alternativa atual para prover o desenvolvimento macroeconômico do Estado.

No entanto, a democratização do acesso à água ainda não é uma realidade plena no Estado, sobretudo para a população rural difusa e pequenas localidades no interior, caracterizando um ambiente de insegurança hídrica, no qual se compreende o conceito de segurança hídrica como água em quantidade, qualidade e regularidade suficiente para

O SISAR possui uma página na Internet disponível no endereço: http://www.sisarceara.org/

Democratisation of Water And Sanitation Governance by Means of socio-Technical Innovation. 
atender à demanda. A restrição ao acesso se dá não somente pela má distribuição dos recursos hídricos, mas também pela desigualdade socioeconômica da população.

Segundo Silva et al. (2013), programas de abastecimento de água rural, como o SISAR, podem atender a vários critérios de sustentabilidade, e ser replicadas para além de comunidades individuais.

No caso específico do Distrito de Cristais, objeto do presente estudo, anteriormente à implantação do SISAR, não existia sistema público de abastecimento de água, sendo a comunidade abastecida precariamente por poços, chafarizes ou carros pipa. Excluindo-se a água encaminhada pela rede de distribuição atual, outras práticas de abastecimento de água dependem geralmente de: 1) cheias naturais do rio Pirangi, que com $117 \mathrm{~km}$ de extensão, representa o principal rio da Bacia Hidrográfica do Pirangi, na qual está localizado o Distrito de Cristais (SILVA, 2012). 2) águas pluviais, cuja precipitação média local, medida pela Fundação Cearense de Meteorologia e Recursos Hídricos (FUNCEME), se situa na faixa de aproximadamente $800 \mathrm{~mm}$ (FUNCEME, 2015). 3) águas subterrâneas, e 4) transporte da água por autoridades governamentais, em carros pipa. Abastecendo-se manualmente junto ao rio Pirangi com um ou vários recipientes, o habitante pode ser levado a percorrer um trajeto curto, algumas centenas de metros, ou ainda vários quilômetros, em função de sua localização geográfica, conforme as informações do relatório do projeto DESAFIO (BROWN, 2014).

O Projeto DESAFIO, financiado pela União Europeia, visa facilitar um acesso melhor à água e ao saneamento no continente sul americano através da pesquisa de campo. Na presente ocasião, o Desafio estudou a comunidade local ao longo de 22 semanas (BROWN, 2014).

Ao longo das décadas de 1980 e 1990, diversos poços públicos foram escavados, por iniciativa de particulares ou do governo, situados próximos do conjunto dos vilarejos. A água de poços é globalmente preferida com relação à água bruta do rio, especialmente porque as pessoas a consideram como sendo mais limpa. Efetivamente, característica local de grande importância, as comunidades se encontram a jusante de vários pontos de infiltração no rio Pirangi por córregos com elevada taxa de salinidade. O resultado é uma água com elevado teor de salinidade que, mesmo pelos serviços do SISAR, não é efetivamente recomendada para o consumo humano.

Segundo Brown (2014), dentre os dados resultantes das análises de água, referentes às nove cisternas e chafarizes coletivos para abastecimento da comunidade, seis fontes (aproximadamente 67\%) indicaram a presença de E. coli. Em síntese, como as cisternas coletivas são abastecidas por caminhões pipas com água tratada ou, pelo menos, clorada, deveria se encontrar uma água de boa qualidade. Possivelmente, a contaminação das cisternas deve estar relacionada a seu manuseio, à utilização de baldes contaminados e ao frequente contato de mãos contaminadas com a água.

Ainda segundo dados de Brown (2014), em aproximadamente 41\% das residências do Distrito, o consumo per capita de água estava situado na faixa de 20 a 50 litros/habitante/dia, valor considerado de risco alto à saúde. Ainda nesta localidade, $28,5 \%$ dos domicílios, consumiam volumes inferiores a 20 litros/habitante/dia, o que pode implicar em elevado risco à saúde. Após a implantação do SISAR, cerca de 75\% das residências de Cristais passaram a consumir valores bem acima do valor de referência de 50 litros/habitante/dia.

Em 2012, com o SISAR, a rede de distribuição foi renovada quase completamente, em decorrência de investimentos oriundos da Fundação Nacional de Saúde (FUNASA). A intenção das renovações era criar uma rede mais ampla que atenderia casas individuais do conjunto das comunidades do entorno.

Foram construídas novas canalizações, partindo-se da estação de tratamento, até os terrenos dos usuários. Cada casa foi equipada com um hidrômetro, que compreende ao objeto técnico de importância central no modelo de gestão do SISAR (BROWN, 2014).

A vazão de projeto, considerando a demanda per capita de 100 litros/habitante/dia, e portanto, no mínimo o dobro do consumo anterior ao SISAR, para a população atual de 1578 habitantes, está estimada em 2,2 litros por segundo, o que representa um volume de $190 \mathrm{~m}^{3}$ por dia, a ser captado a partir do Canal da Integração. Para um horizonte de 20 anos, estima-se um crescimento populacional na taxa de $2,00 \%$ ao ano, o que representará um volume de captação na ordem de $281 \mathrm{~m}^{3}$ de água por dia. Para garantir o abastecimento, foram instalados 18.277 metros de rede de distribuição, 344 ligações prediais, e construídos a estação de tratamento e o reservatório.

A partir do SISAR, a água passou a ser captada no Canal da Integração (Figura 1, 2), responsável pelo abastecimento da Região Metropolitana de Fortaleza, localizado a dois quilômetros de distância do Distrito de Cristais. O manancial de captação apresenta vazão suficiente para atender a demanda necessária à população da comunidade, em conformidade com a estimativa calculada em projeto. 
Figura 2 - Captação de água bruta no Canal da Integração para abastecimento do Distrito de Cristais.

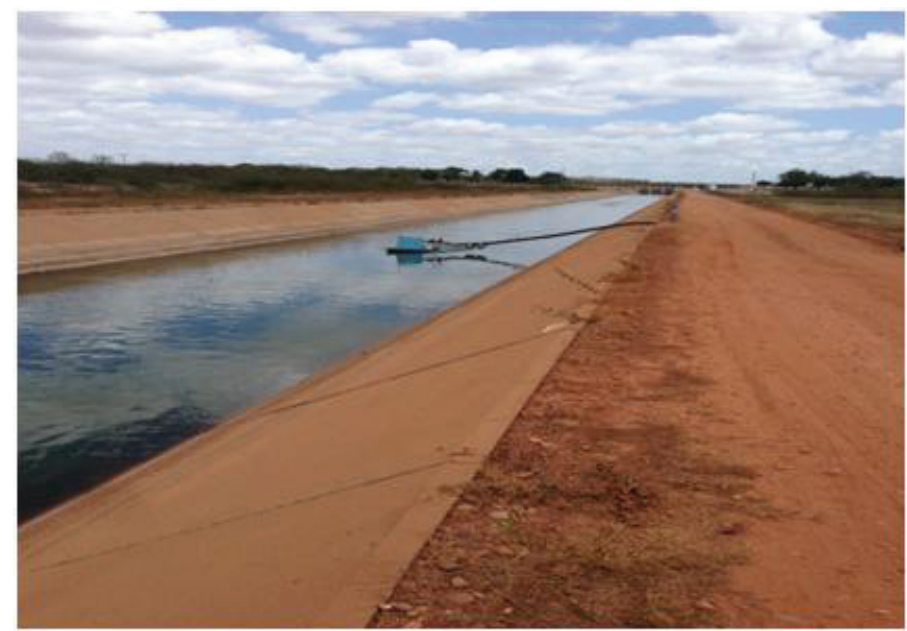

Fonte: Alves (2015)

Após o tratamento da água, a mesma é recalcada para o reservatório elevado situado no ponto mais alto da localidade (Figura 3a; 3b). Do reservatório elevado à água chega aos domicílios através da rede de distribuição.

Figura 3 - Aspectos gerais da estrutura de abastecimento: a) dosador de cloro em uma das etapas do tratamento e b) reservatório de água para distribuição.
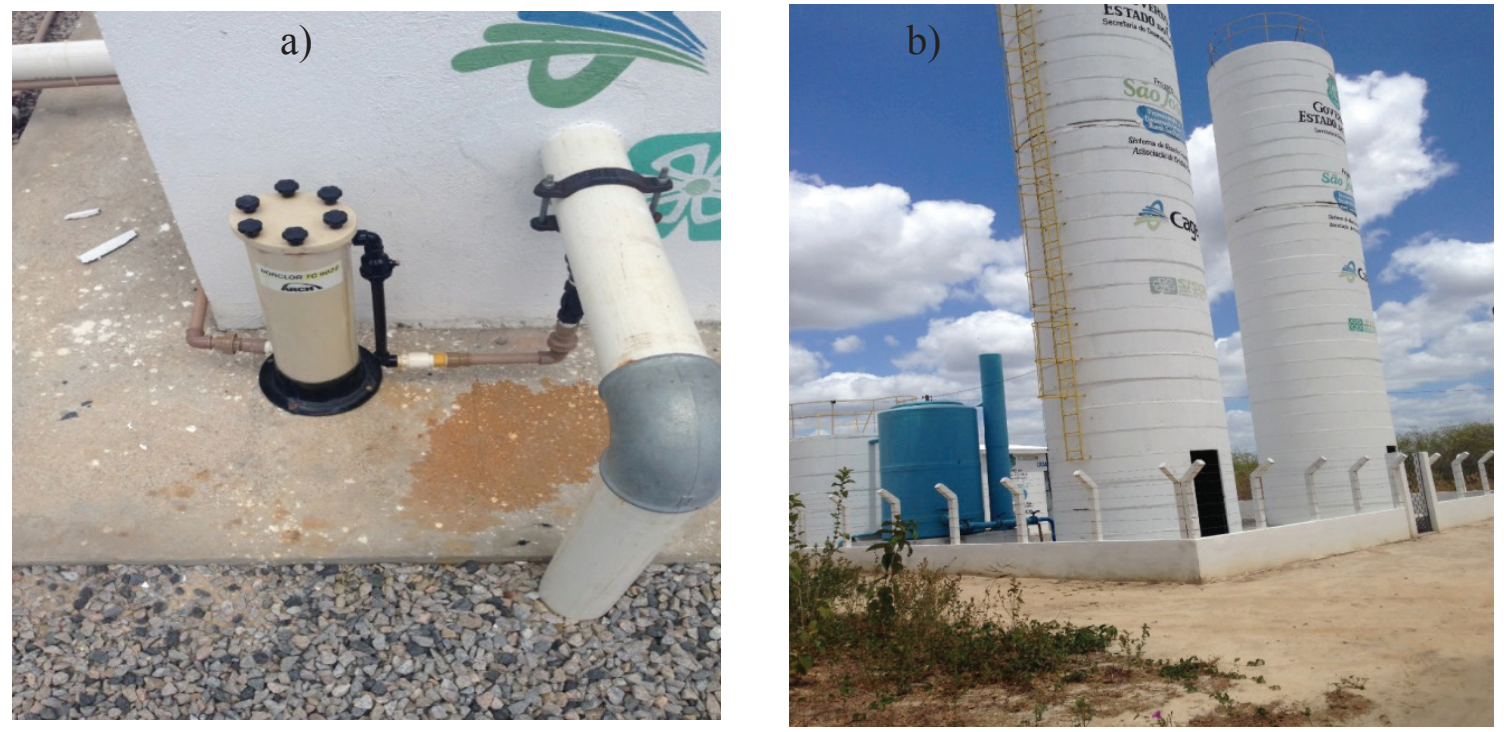

Fonte: Alves (2015).

Foi constatado que algumas residências da comunidade não possuem o sistema de abastecimento de água SISAR, em função de tais moradores, por falta de informações ou por fatores culturais, não achar necessário; as residências ainda contam com os sistemas existentes de abastecimento na comunidade como cisternas, poços, chafarizes e carros pipa, assim como não desejam pagar a tarifa pelo serviço de abastecimento.

Com a observação de campo foi possível constatar, através das contas de água dos consumidores da comunidade, que um percentual $(10,8 \%)$ das famílias que foram contemplados e usam o sistema SISAR consomem valores diários abaixo de 50 litros/habitante/dia. 
A tarifa mínima cobrada nas comunidades abastecidas pelo Sistema SISAR, conforme levantamento de campo, realizado em setembro de 2015, é de $\mathrm{R} \$ 12,24$, pelo volume mínimo de $10 \mathrm{~m}^{3}$ por mês.

Foram avaliadas residências com consumo médio de $6 \mathrm{~m}^{3} / \mathrm{mês}$. Foi observado que muitas desses domicílios possuem apenas um ponto de água e, de modo geral, o ponto de coleta é uma torneira instalada no cavalete do hidrômetro (Figura 4).

Assim, as famílias têm que transportar a água para dentro da estrutura habitacional, mesmo que seja por meio de mangueira, para encher seus contentores, o que pode contaminar a água no interior das próprias residências. É necessário, portanto, a instalação de infraestruturas hidráulicas nas residências, para que se tenha uma elevação dos valores de consumo de água, com a melhoria das condições de higiene, diminuindo a vulnerabilidade às doenças associadas ao consumo de água.

A ausência de pontos em locais no interior das residências como cozinhas, banheiros, lavanderias, revela a forma em que estas pessoas se relacionam com a água. Além disso, muitos destes moradores ainda se utilizam no seu dia a dia, da obtenção de água obtidas por meio de cisternas de placas ou coletam em poços ou chafarizes da própria comunidade e de carros pipa, mesmo tendo o SISAR nas suas residências.

Tal cenário mostra que é de suma importância a instalação de infraestrutura hidráulica nas residências, para que se tenha uma elevação dos valores de consumo por habitante, diminuindo sua vulnerabilidade hídrica, assim como uma mudança de aspectos culturais.

Figura 4 - Hidrômetro instalado em uma residência com apenas um único ponto de acesso à água.

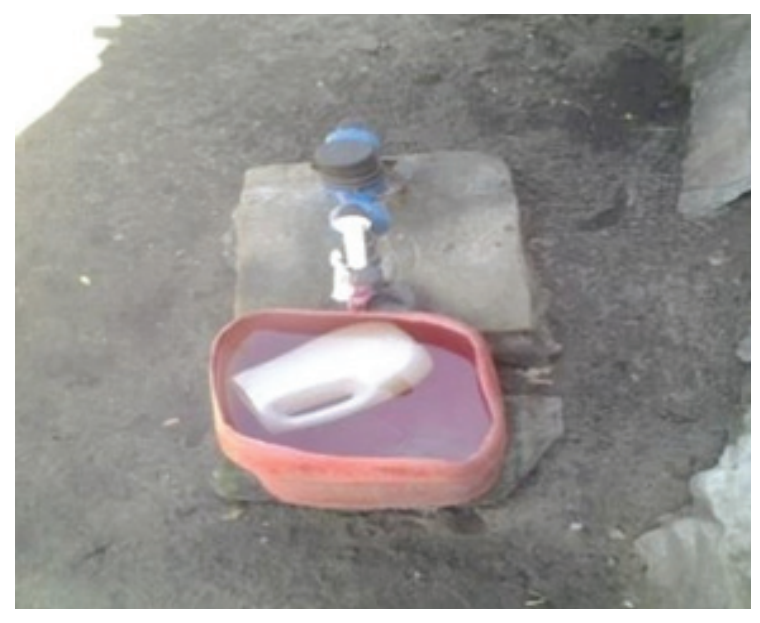

Fonte: Alves (2015)

Observou-se também que, concomitantemente ao projeto de abastecimento de água, há um projeto do Governo do Estado, com o apoio do SISAR, para a implantação de 209 domicílios da comunidade, que irão receber módulos sanitários, a fim de promover uma destinação adequada dos dejetos domicilares.

$\mathrm{Na}$ pesquisa de campo foi observado que, possivelmente, existem ligações clandestinas, que desviam água do sistema de abastecimento de água do SISAR, comprometendo a sustentabilidade do sistema.

\section{Conclusão}

A partir da análise da instalação do sistema de abastecimento de água SISAR em uma pequena comunidade rural do Semiárido brasileiro, é possível elencar os seguintes pontos:

- O SISAR representou um avanço para melhoria ao acesso à água, pois a comunidade, mesmo pouco distante de um grande sistema de abastecimento, o Canal do Trabalhador, não era beneficiada pelo mesmo.

- A diferença nos volumes de água consumidos antes e depois da implementação do SISAR na comunidade demonstra mudanças nos hábitos de higiene. Os maiores volumes de água são um importante fator na melhoria dos indicadores de saúde. 
- Apesar de ser um impulso à comunidade rural ter um sistema de abastecimento de água gerido pelo SISAR, outras ações, incluindo infraestrutura domiciliar, serão necessárias para ampliar o avanço no acesso à água.

- Questões culturais, impedindo que os moradores passem a utilizar o Sistema, em detrimento de outras fontes alternativas de abastecimento, precisam ser estudadas, assim como do esclarecimento, por parte dos usuários, em relação às cobranças tarifárias da água disponibilizada, incluindo a verificação de suas capacidades de pagamento.

\section{Referências}

ALBUQUERQUE NETO, V. S. Análise do SISAR como uma alternativa financeiramente sustentável para o saneamento rural no Ceará. 2011. 74f. Dissertação (Mestrado) - Universidade Federal do Ceará, Fortaleza, 2011.

ALVES. F. G. C. Abastecimento de comunidades rurais do semiárido nordestino: o caso da Comunidade de Cristais, Cascavel/CE. 2015. 79f. Trabalho de Conclusão de Curso (Graduação em Engenharia Ambiental) - Universidade de Fortaleza, Fortaleza, 2015.

ARAÚJO, F. T. V.; Nunes, A. B. A.; SOUZA FILHO, F. A. Desertificação e pobreza: existe um equilíbrio de baixo nível? Revista Econômica do Nordeste, Fortaleza, v. 45, n. 1, p. 106-119, jan./mar., 2014.

ARAÚJO, F. T. V. et al. La implantación de un sistema de abastecimiento en una comunidad rural de semiárido brasileño. In: CONGRESO INTERAMERICANO DE AGUA POTABLE Y SANEAMIENTO RURAL, 2, 2016, Santiago. Anais... Santiago: AIDS, 2016. p. 36. Disponível em: $<$ http://www.aidis.org.br/PDF/informe_ IICongresoAPR.pdf > . Acesso em: 24 jun. 2016.

BASE de dados pluviométricos. Disponível em: <www.funceme.br >. Acesso em 15 nov. 2015.

BRASIL. Constituição (1988). Constituição da República Federativa do Brasil. Brasília, DF: Senado Federal, 1988.

. Lei $n^{\circ}$ 9.433, de 08 de janeiro de 1997. Institui a política nacional de recursos hídricos, cria o sistema nacional de gerenciamento de recursos hídricos. Diário Oficial da União, Brasília, DF, 9 jan. 1997. Disponível em: <http://www. planalto.gov.br/ccivil_03/leis/L9433.htm>. Acesso em: 1 dez. 2015.

. Lei ${ }^{\circ} 11.445$, de 05 de janeiro de 2007. Estabelece diretrizes nacionais para o saneamento básico. Diário

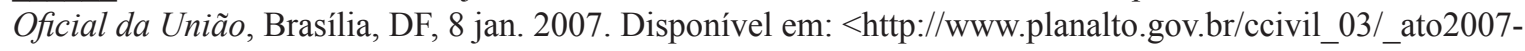
2010/2007/lei/111445.htm>. Acesso em: 1 dez. 2015.

. Ministério da Saúde. Portaria no 2914, de 12 de dezembro de 2011. Dispõe sobre os procedimentos de controle e de vigilância da qualidade da água para consumo humano e seu padrão de potabilidade. Diário Oficial da União, Brasília, DF, 11 dez. 2011. Disponível em: <http://bvsms.saude.gov.br/bvs/saudelegis/gm/2011/prt2914_12_12_2011. html>. Acesso em: 1 dez. 2015.

BROWN, C. Democratisation of Water and Sanitation Governance by Means of Social-Technical Inovation. Um sistema comunitário da gestão da água: abordagem sociotécnica da inovação, Ceará, Brasil, 2014. Cadernos de Trabalho da Rede Waterlat Gobacit, Reino Unido: Waterlat Gobacit, v. 2, n. 6, p. 69-162. (Projetos de Pesquisa).

CRUZ, B. A. S. O efeito do acesso à água na área rural na redução da vulnerabilidade: o caso do SISAR/CE. 2015. 157f. Dissertação (Mestrado em Saneamento, Meio Ambiente e Recursos Hídricos), Universidade Federal de Minas Gerais, Belo Horizonte, 2015.

DANTAS NETO, S.A., SILVA, F. O. E. D.; SOUZA FILHO, F. A. Condicionantes para universalização e sustentabilidade do abastecimento d'água para pequenas comunidades rurais difusas no semiárido brasileiro. In: SIMPÓSIO BRASILEIRO DE RECURSOS HÍDRICOS, 20., 2013, Bento Gonçalves. Anais....Bento Gonçalves: ABRH, 2013. p. 1-8. Disponível em: <https://www.abrh.org.br/SGCv3/UserFiles/Sumarios/ c625e2a1 eacf5c79ac41d5a89d02cf93_e0c5d90b8928c59219c9ca3d4d6cd39a.pdf>. Acesso em: 13 jun. 2016.

DESAFIO: democratização da governança dos serviços de água e esgotos por meio de inovações sociotécnicas. Disponível em: < http://desafioglobal.org/pt/>. Acesso em: 13 dez. 2015.

IBGE. Instituto Brasileiro de Geografia e Estatística. 2010. Disponível em: < http://cidades.ibge.gov.br/xtras/ uf.php? coduf $=23>$. Acesso em: 11 dez. 2015.

MELEG, A. SISAR: An Innovative Sustainable Management Model for Small Decentralized Water and Wastewater Systems in Developing Countries. Disponível em: <http://w.macsonline.de/ivs/fileadmin/macs_data/Media/SISAR_ article_AM.pdf>. Acesso em: 20 jun. 2016. 
Francisco Glauber César Alves, Flávia Telis de Vilela Araújo

MELEG, A. SISAR: A sustainable management model for small rural decentralized water and wastewater systems in developing countries. Journal of Water Sanitation and Hygiene for Development. United Kingdom, v. 2, n.4, p. 291300, dec. 2012

ROCHA, W. D. S. Estudo de caso do sistema integrado de saneamento rural (SISAR) no Brasil. [S.1.]: BID, 2013.

SILVA, F. O. E. Plano de águas municipal como instrumento de política pública para universalização do abastecimento de pequenas comunidades rurais do semiárido cearense. $2011.182 \mathrm{f}$. Tese (Doutorado) - Universidade Federal do Ceará, Fortaleza 2011.

SILVA, F. O. E. et al. Developing sustainable and replicable water supply systems in rural communities in Brazil. International Journal of Water Resources Development, [S.1.], v. 29, n. 4, p. 622-635, 2013

SILVA, J. M. O. Análise integrada da Bacia Hidrográfica do Rio Pirangi-CE: subsídios para o planejamento ambiental. 2012. 271f. Tese (Doutorado em Geografia) - Universidade Federal do Ceará, Fortaleza, 2012.

SISTEMA Integrado de Saneamento Rural. Disponível em: <http://www.cagece.com.br/2013-01-28-19-25-06/sisar>. Acesso em: 5 jan. 2016.

Sobre os autores

\section{Francisco Glauber César Alves}

Engenheiro Ambiental, Universidade de Fortaleza - UNIFOR. Engenheiro de Pesca, Universidade Federal do Ceará UFC.

\section{Flávia Telis de Vilela Araújo}

Engenheira de Materiais, Universidade Federal da Paraíba - UFPB. Mestre e Doutora pela Universidade Federal do Ceará - UFC. Prof. de Saneamento Ambiental do Centro de Ciências Tecnológicas da Universidade de Fortaleza UNIFOR. Professora do Centro Universitário Estácio do Ceará. 